Caligrama, Belo Horizonte, v. 23, n. 2, p. 217-230, 2018

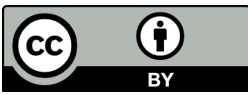

\title{
Da coleção à alegoria: a fragmentação e outras tendências da literatura brasileira contemporânea em Esquilos de Pavlov, de Laura Erber
}

\section{From collection to allegory: fragmentation and other tendencies of contemporary Brazilian literature in Esquilos de Pavlov by Laura Erber}

\author{
Maria Isabel Rios de Carvalho Viana \\ Centro Federal de Educação Tecnológica de Minas Gerais, Belo Horizonte, Minas \\ Gerais / Brasil \\ mariaisabel@div.cefetmg.br
}

Resumo: O objetivo deste artigo é analisar o romance Esquilos de Pavlov, da escritora e artista visual Laura Erber, com vistas a identificar algumas tendências da literatura brasileira contemporânea e mostrar de que forma a autora reúne fragmentos de sua coleção e cria, em um procedimento alegórico, uma metaficção influenciada pelo surrealismo para questionar o conceito de arte, a identidade do artista e as fronteiras da literatura. Para tal, a leitura da obra se fez a partir de teorias sobre a condição contemporânea da literatura brasileira bem como de textos de Benjamin (2006) que discutem o trabalho do colecionador e do alegorista.

Palavras-chave: Esquilos de Pavlov; Laura Erber; literatura brasileira contemporânea.

Abstract: The aim of this article is to analyze the novel Esquilos de Pavlov by the writer and visual artist, Laura Erber, in order to identify some tendencies of contemporary Brazilian literature. In addition, we aim to show how the author gathers fragments of her collection and creates, in an allegorical procedure, a metafiction influenced by surrealism to question the concept of art, the identity of the artist and the boundaries of literature. This analysis was made based on theories about the contemporary tendencies of Brazilian literature and on Benjamin (2006) texts that discuss the work of the collector and the allegorist.

Keywords: Esquilos de Pavlov; Laura Erber; contemporary Brazilian Literature. 


\section{Introdução}

Como disse Benjamin (2006, p.245), “colecionar é um fenômeno primevo do estudo: o estudante coleciona saber." Foi como estudante de letras e literatura, e a partir de experiências de residências artísticas na Europa que Laura Erber começou a construir sua coleção de fotografias, histórias, leituras e obras de arte que compõem a obra Esquilos de Pavlov, primeiro romance da autora, publicado em 2013. Transitando entre a literatura e as artes visuais, os projetos da artista e escritora abordam a relação entre a imagem e a palavra, mostrando como ambas interferem na percepção uma da outra. O romance corrobora seus projetos e dialoga com outras de suas obras, bem como com trabalhos de artistas que fizeram parte dos estudos de Erber, dentre eles o poeta surrealista Ghérasim Luca.

Narrado em primeira pessoa, Esquilos de Pavlov é uma metaficção que conta a história do jovem romeno Ciprian Momolescu, um aspirante a artista que passou a viver de bolsas artísticas pela Europa e, com isso, acabou cruzando com artistas do mundo real. Trata-se de um livro que causa estranhamento, não apenas pela sua ambientação na Romênia, mas também pela estratégia narrativa adotada e pelas fotografias que o compõem. O objetivo deste artigo é, assim, analisá-lo, identificando algumas tendências da literatura brasileira contemporânea e mostrando de que forma a autora utiliza de sua coleção e cria, em um procedimento alegórico, uma metaficção crítica para discutir a arte e questionar os limites de uma literatura brasileira. Para tanto, a análise da obra darse-á em torno de duas linhas teóricas principais: a discussão sobre o contemporâneo, empreendida por Agamben (2009), e a abordagem sobre a coleção, o trabalho do colecionador e do alegorista, retirada dos textos de Benjamin (2006)

\section{Laura Erber: de colecionadora a alegorista}

"Minha mente parecia um esquilo. Eu juntava e juntava coisas, e depois as escondia, para quando chegasse um longo inverno." (MANSFIELD apud ERBER, 2013a, p. 10)

A imagem dos esquilos recolhendo e escondendo coisas nessa citação de Katherine Mansfield, usada por Laura Erber como epígrafe de seu romance, faz referência não apenas ao título Esquilos de Pavlov, 
mas também ao próprio processo de criação da autora, que, por um tempo, foi colecionando histórias, fatos, fotografias, textos e saberes que foram, posteriormente, utilizados em sua obra. Esta epígrafe serve também para se referir à própria estratégia narrativa usada por Ciprian, $\mathrm{o}$ narrador-protagonista, e à forma como o leitor vai construindo sua leitura: de início, por exemplo, Ciprian apenas cita o nome dos personagens que fizeram parte da sua história, e, somente mais à frente, o leitor terá ideia do que acontece com eles ou do seu papel na narrativa. Essa estratégia exige um leitor atento, que guarde as pistas e as várias referências que o texto traz para tentar construir algum significado posteriormente. Isso acaba também por incitar mais leituras do livro, pois, a cada leitura, um novo elemento é percebido e incorporado.

Como uma metaficção, tipo de narrativa que, segundo Schøllhammer (2009, p. 129), "vem explicitar a atenção autoconsciente da natureza construtiva da ficção", Esquilos de Pavlov constitui uma tendência da literatura brasileira contemporânea. No romance, o narrador faz reflexões a respeito de como sua narrativa deve se dar, admitindo a ajuda de uma mulher em seu projeto. Citada no início, somente ao final se descobre que essa mulher seria sua companheira, com quem, no momento da escrita, Ciprian dividia sua vida. Pelas colocações do narrador, podese inferir, ainda, um desejo de se tornar escritor e publicar tal estória.

A mulher que me questiona sorrindo diz que saberia contar a minha estória, que seria parecido com andar de bicicleta com uma mão só ou dançar na borda de um lago. Se isso a satisfaz pode fazer o que quiser com a minha vida. Surpresa com minha resposta o sorriso dela desaparece. Ela não é, nunca quis, nunca pensou em ser artista, criar, assinar, publicar, dedicar. Digo a ela que isso também a coloca numa posição vantajosa com relação a mim mas não chega a ser uma garantia. (ERBER, 2013a, p.16)

É também recorrente no livro a presença de personagens reais e a referência a fatos históricos. A narrativa de Ciprian faz menção ao regime comunista de Nicolae Ceausescu, uma época marcada pela aniquilação da individualidade e da subjetividade. Conforme o narrador afirma em sua ficção de origem, ele nasceu em uma época e em condições nas quais não se tinha boas perspectivas para o futuro. Não era desejado pelo pai, Spiru, um artista frustrado que ganhou a vida escrevendo histórias infantis de um Ursinho Metalúrgico que vivia confinado. A mãe, Nicoleta, por sua 
vez, uma mulher sem coragem e indecisa, não vislumbrava alternativa a não ser ter o bebê, pois, segundo o discurso comunista com que Ciprian inicia sua narrativa, "[o] feto é uma propriedade de toda a sociedade. Dar à luz é um dever patriótico decisivo para o desenvolvimento da nação. Aqueles que se recusam a se tornarem pais são desertores voando para longe das leis da continuidade do [...] povo" (ERBER, 2013a, p.11). Durante a ditadura Ceausescu, as mulheres eram submetidas a exames ginecológicos obrigatórios para impedi-las de cometer aborto, pois era meta do governo aumentar a população da Romênia.

Nesse contexto histórico, Ciprian se torna aluno do curso de belasartes, ideia que o pai não aprova, talvez pelas decepções que sofrera como artista: "Você começa sua arte como um esquilo travesso mas acabará como um grande charlatão, Ciprian" (ERBER, 2013a, p.40). Adiante, decepcionado com o que viu na faculdade e sendo contratado para trabalhar como secretário na Biblioteca de Bucareste, Ciprian abandona o curso. Depois disso, é chamado a fazer intervenções em bibliotecas. Essas intervenções é que acabam lhe dando bolsas e permitindo que ele fizesse parte de residências artísticas pela Europa:

A maior parte das pessoas nunca teria visto arte se não conhecesse essa palavra. Em 1986 comecei a fazer coisas que por inércia ou petulância receberam esse nome. Uma curadora de Lubliana disse estupendo estupendo e foi fogo se alastrando. Pela primeira vez eu recebia convites para sair de Bucareste. Fiz intervenções nas bibliotecas de Chisinau, Cracóvia e Lubliana, até que um dia recebi uma bolsa do governo sueco, um programa de artista em residência. (ERBER, 2013a, p.55)

Enquanto narra as histórias de sua vida e de suas viagens, Ciprian faz referência a vários espaços reais por onde transitam personagens fictícios. Esses, por sua vez, relacionam-se com artistas reais citados na obra, como os poetas Paul Paun, Gellu Naum e Ghérasim Luca, que formaram o grupo responsável por introduzir o surrealismo na Romênia. Além disso, obras e documentos fictícios coexistem com obras reais. São várias as referências a livros, filmes, textos, artistas, documentários, deixando transparecer o trabalho de pesquisa da autora e os elementos que ela foi acumulando em sua coleção.

No que se refere ao ato de colecionar, Benjamin (2006, p.239) afirma que, para fazer parte de uma coleção, "o objeto deve ser desligado 
de todas as funções primitivas." O colecionador verdadeiro retira o objeto de sua função e consegue lançar sobre ele um outro olhar, "um olhar que vê mais e enxerga diferentes coisas do que o olhar do proprietário profano" (BENJAMIM, 2006, p.241). Como colecionadora de fotos, Laura Erber retira delas a função de retratar um fato ou imortalizar um momento e as acrescenta à narrativa como o faria um alegorista. Enquanto o colecionador busca uma solução para a confusão e a dispersão das coisas do mundo, unindo-as com o objetivo de dar completude à coleção, o alegorista, segundo Benjamin (2006, p.245), "desistiu de elucidar as coisas através da pesquisa do que lhes é afim e do que lhes é próprio. Ele as desliga de seu contexto e desde o princípio confia na sua meditação para elucidar seu significado.” Apesar de diferenciá-los, Benjamin (2006, p.245) afirma que

[...] em cada colecionador esconde-se um alegorista e em cada alegorista um colecionador. No que se refere ao colecionador, sua coleção nunca está completa; e se lhe falta uma única peça, tudo que colecionou não passará de uma obra fragmentária, tal como são as coisas desde o princípio para a alegoria. Por outro lado, justamente o alegorista, para quem as coisas representam apenas verbetes de um dicionário secreto, que revelará seus significados ao iniciado, nunca terá acumulado coisas suficientes, sendo que uma delas pode tanto menos substituir a outra que nenhuma reflexão permite prever o significado que a meditação pode reivindicar para cada uma delas.

O alegorista é capaz de fazer uma coisa significar outra, ele pode atribuir um outro sentido a um fragmento. Como alegorista, Laura Erber constrói uma narrativa fragmentada, que se faz a partir de outras narrativas, de poemas e também de fotos que não têm como função ilustrar o texto (conforme a autora ressalta em entrevistas, muitas vieram antes da matéria verbal), mas explorar a possibilidade semântica das imagens. No livro, a autora explicita a origem das fotografias. Algumas são de sua coleção pessoal. Outras foram solicitadas do arquivo de amigos e parentes. No livro, a imagem não necessariamente diz respeito ao que está sendo narrado naquela página, mas, adiante, pode precisar ser retomada por ter alguma relação com o que está sendo dito. Cabe ao leitor estabelecer essa relação, pois elas formam uma espécie de colagem com o texto e com outras obras de arte que lhe chegam através da palavra. À primeira vista, esses fragmentos que compõem a obra parecem descontextualizados e 
insignificantes. Porém, à medida que se vai tendo acesso ao todo, eles começam a fazer sentido. E é neste processo de construção de sentido que a narrativa de Ciprian se faz. Segundo Junkes (1994, p.130), em um texto sobre o processo de alegorização nas teorias de Walter Benjamim,

[é] a alegoria que liberta a coisa do seu aprisionamento num contexto funcional no qual não tem sentido próprio, mas somente como parte dum todo, como elemento do contexto. Arrancando as coisas do seu contexto e colocando-as em novos e diversos contextos, o alegorista, com sua descontextualização e recontextualizações arbitrárias, indica que o sentido atribuído à coisa do contexto específico não é o original e inato, mas arbitrário.

Pensando no processo de constituição de sentido dessa narrativa, que se dá pela montagem de fragmentos diversos e que têm como princípio fundamental o envolvimento da subjetividade para que um sentido se estabeleça, é possível pensar em Esquilos de Pavlov como uma alegoria. Essa se apresenta como uma técnica de construção estética e uma forma de interpretação das coisas bastante utilizada pelos movimentos de vanguarda. Esses movimentos normalmente nascem como uma ruptura com formas de arte anteriores e se rebelam contra um discurso de arte que, de certa forma, segue a ordem vigente na sociedade. Nas vanguardas, a linguagem perde sua função representativa e o receptor das obras de arte é desafiado, enquanto se exalta a subjetividade e a livre criatividade do artista. As vanguardas ainda se caracterizam por um espírito decadente e por um conceito de arte sem fronteiras.

Ciprian, em suas viagens, relata o contato com vários artistas de vanguarda. Seu pai Spiru, apesar de ter tido um "mau encontro com o surrealismo" (ERBER, 2013a, p.19), havia colaborado para o movimento, juntando sucata para Ghérasim Luca. O surrealismo foi uma importante corrente vanguardista que se ocupou de recolher fragmentos e objetos fora de moda e sem utilidade, justapondo-os em um procedimento alegórico. A narrativa de Ciprian possui várias características que permitem associá-la ao movimento. Uma dessas características é a semelhança da narrativa a uma escrita automática do fluxo de consciência, que permite desnudar a forma de funcionamento real do pensamento. O texto é descontínuo e sua estrutura é fragmentada, cheia de interrupções que remetem ao ritmo do ato de pensar. 
Ao recorrer a uma montagem de fragmentos desconexos da realidade e a associações espontâneas de imagens, o texto faz referência à arbitrariedade das imagens e ainda ao tema do acaso, ambos abordados pelos surrealistas. Para Ciprian, "[h]á momentos na vida de qualquer pessoa que parecem tão iguais aos outros, tão sem interesse, tão banais, e no entanto aí também pode estar acontecendo algum fenômeno irreversível. É o caso do musguinho"(ERBER, 2013a, p.43). A narrativa do musguinho aborda o acaso. Um musguinho, aparentemente insignificante, cresce sobre uma pedra e acaba causando a morte de alguém que pisa sobre ela, cai e quebra o pescoço. Formada por vários acontecimentos isolados que se justapõem, a narrativa de Ciprian não tem propriamente um enredo. A relação entre as histórias narradas está mais na vivência do narrador que em uma relação lógica entre elas. Trata-se de acontecimentos que se cruzam de forma inesperada, a partir de semelhanças ou coincidências.

Ao utilizar a metodologia surrealista de aproximar realidades distantes, o livro exige que o leitor esteja atento à receptividade do acaso e que seja capaz de observar a coincidência entre elementos tão distintos. Nessa montagem de texto e imagens, o leitor é levado a avançar e retornar, apropriando-se das imagens alegóricas para conferir-lhes um significado, significado este que não consegue abarcar o todo. A livre associação de imagem e texto e a fragmentação remetem às contradições do real. O próprio narrador é um sujeito em contradição: "Não sou o que meus pais temiam mas também não me tornei a pessoa que eu mesmo gostaria de ter sido. Da minha mãe herdei o sono, do meu pai a incapacidade de dormir" (ERBER,2013a, p.17).

Além de trazer à tona a impossibilidade de compreensão total de uma obra, uma vez que é enorme a quantidade de referências no livro, bem como são inúmeras as possibilidades de inferência e associação que se podem fazer, o livro traz uma reflexão sobre a transformação das atividades artísticas e intelectuais e sobre a problemática da arte e seu lugar na cultura contemporânea ante as mudanças do sistema de produção e consumo do objeto artístico. Voltando-se para o conceito de arte, a obra traz um questionamento sobre o que, por condicionamento, pode receber este nome.

O condicionamento como uma forma de alienação do sujeito é referenciado no título da obra pela figura de Ivan Pavlov, que desenvolveu a teoria do comportamento condicionado. Essa ideia aparece também em 
outras passagens do livro, como na referência ao Experimento Pitesti, que Ciprian define como "a aplicação em território romeno do projeto soviético de desumanização e aniquilamento da subjetividade, oficialmente denominado 'reeducação para fins de conversão ideológica' " (ERBER, 2013a, p.150). O narrador descreve com detalhes o processo de tortura que sofriam estudantes de Filosofia, Letras, Direito e Teologia presos pelo governo. As torturas eram elaboradas a partir das teorias de Ivan Pavlov.

Em oposição a este condicionamento imposto pela sociedade e por um governo, estaria a arte como forma de liberdade de expressão, como uma afirmação da subjetividade. Porém, a arte parece deixar de cumprir esse papel. É essa a discussão levantada pelo discurso de Ulrikka Pavlov, uma senhora pensante da Zelândia que discursa para os residentes artísticos, entre os quais está Ciprian. A respeito do fato de a arte estar ligada a um sistema de produção cultural e de mercado que define o que é ou não arte, Ulrikka Pavlov sugere aos seus esquilos:

Abandonem a vida artística. Abandonem a identidade de artistas. Abandonem as obrigações desse sistema que não faz mais do que impedir o artista de se desenvolver plenamente. Esqueçam editais, residências, conferências, jantares com colecionadores, jantares com miliardários, esqueçam amizade dos críticos, contatos com editores, jornalistas de plantão, contatos com contatos de contatos de diretores de museu. [...] Daqui a vinte anos procurarei cada um de vocês. Então veremos os resultados. Sim. Os resultados. A palavra não é boa. Estou certa de que estarão produzindo as obras mais vitais do novo século, aquelas que fogem a todas as expectativas e que por isso mesmo são as únicas capazes de atender às necessidades poéticas, políticas e estéticas da nossa época. (ERBER, 2013a, p.122)

O discurso de Ulrikka Pavlov, perdido no tempo e recuperado por Ciprian e seus companheiros, que preenchem suas lacunas com referências bibliográficas sobre arte, leva os estudantes a fazerem questionamentos sobre qual atitude teriam com relação à arte e sua identidade de artista:

O problema não era o que faríamos ou deixaríamos de fazer, mas se nos importaria muito ou muito pouco passar da arrogância de um "sou artista, logo existo" à falácia, "existo, sou e nas horas de afluência enquanto todos se preocupam com presentes de Natal 
eu faço minha arte, mas não é nada, não é nada, são só umas coisinhas que me distraem do peso de viver e da arrogância de pensar. E eis que retornamos ao ponto de partida. Se romper o cerco do sistema de arte significava transformar nossos gestos numa espécie de mistério petulante, numa atividade não assumida como diferente das demais mas que continuava a diferenciar o criador do açougueiro, realmente era preferível deixar as coisas como estavam. (ERBER, 2013a, p.126)

Ciprian foi vítima desse sistema. Ele próprio só conseguiu se tornar um artista e sobreviver como tal participando de residências artísticas e com a influência da maçonaria, sociedade da qual seu pai, Spiru, participava. Este, por sua vez, conforme Ciprian descobre enquanto fazia intervenções na biblioteca Jacques Doucet, em Paris, havia tentado inutilmente a influência do renomado Ghérasim Luca para ir à capital francesa trabalhar como artista. Ciprian toma conhecimento desse fato ao encontrar nos arquivos uma carta enviada por seu pai ao poeta.

Apesar da ajuda da maçonaria, Ciprian se apresenta como um artista que não conseguiu ser bem-sucedido. O livro traz o circuito melancólico da arte contemporânea e apresenta um artista em decadência: "Era uma vez um artista contemporâneo e os abismos que arrastava por onde ia" (ERBER, 2013a, p.16). Em uma necessidade de organizar este pessimismo, Ciprian faz sua narrativa com desconfiança da liberdade. Os Esquilos de Pavlov são livres para fazer sua arte, ou ela está condicionada a um sistema? Seria possível fugir desse sistema? A fuga seria a verdadeira arte, mas esta seria reconhecida como tal? Seria o início do processo de degradação da arte? Ou a arte sempre se fez dessa forma?

Essa discussão sobre a arte também pode ser estendida ao mercado editorial. Em sua narrativa, de uma maneira bastante irônica, Ciprian faz uma crítica ao condicionamento e à repetição de um padrão dos livros bestseller. Pernille, uma mulher com quem Ciprian teve um caso amoroso, havia se tornado uma escritora bem-sucedida seguindo uma fórmula de sucesso.

Uma enorme livraria, com muitas vitrines enfeitadas, e numa delas havia centenas de exemplares de um livro de capa preta com uma imagem de uma noz em alto-relevo, funcionando como ponto para o i de... Pernille. Coincidência cabalística. Era a própria! E pela capa do livro, devia ser a mais recente maravilha da pior espécie de literatura. Já o título condensava uma série de qualidades sutis e muito sonoras, Mistério no Carmelo, e a heroína só poderia ser o que 
era: uma carmelita descalça que salvava garotos judeus famintos de um campo de extermínio transportando clandestinamente nozes na xoxota. Já era um best-seller. (ERBER, 2013a, p.163)

A ironia está presente em toda a narrativa, que não traz respostas ou soluções para a problemática da arte e da literatura, mas suscita perguntas e questionamentos importantes para se pensar esses assuntos na contemporaneidade.

\section{A arte e a literatura brasileira contemporânea}

Laura Erber elaborou Esquilos de Pavlov como uma ficção teórica narrada pela voz de um artista contemporâneo. O filósofo Giorgio Agamben (2009, p.64) se ocupou, em sua obra, de definir o que seria o contemporâneo: "o contemporâneo é aquele que percebe o escuro do seu tempo como algo que lhe concerne e não cessa de interpelá-lo, algo que, mais do que toda luz, dirige-se direta e singularmente a ele". O escuro de uma época é aquilo que precisa ser explicado e, ao fazer sua ficção dessa forma, Laura Erber tem a liberdade de teorizar sobre os escuros da arte contemporânea sem ter que se preocupar com o documental ou o factual. Em uma entrevista ao Suplemento Pernambuco, quando perguntada sobre o porquê de ter escolhido a prosa de ficção ao invés do ensaio para tratar da arte contemporânea, Laura Erber responde:

Porque estava lidando com o que não é documentável, o que está latente. A história e a crítica de arte em geral lidam com o que existe, e me interessa pensar essa zona de sombra, em que o que existe é ativado pelo que não existe de fato mas existe como possibilidade. E porque queria captar o presente, não apenas o presente do narrador, mas na sua dimensão de contemporaneidade. [...] A vida de Ciprian e o seu olhar revelam e questionam um determinado modelo de vida artística, no que ele tem de paradoxal. Eu realmente não queria trabalhar desde um ponto de vista exterior, de fazer uma avaliação desde fora, queria criar uma intimidade crítica e afetiva com esse mundo, mostrando o descompasso entre uma certa ideia da arte contemporânea e a prática da sua circulação. (ERBER, 2013b)

Ao sair do âmbito puramente literário, em Esquilos de Pavlov, Laura Erber usa a escrita ficcional como uma forma de fazer crítica e 
questionar os limites da literatura brasileira contemporânea. Muitos teóricos se ocupam em definir e encontrar tendências para este novo momento da literatura brasileira. O que caracterizaria esta literatura? Quais seriam as suas tendências? Beatriz Resende, em seu texto "Possibilidades da nova escrita literária no Brasil", afirma que, devido ao crescimento econômico do país e a sua inserção no mercado editorial global, observa-se uma evidência, nas obras brasileiras, de deslocamento das narrativas do espaço nacional e o rompimento com uma tradição literária de afirmação da nação. Segundo a autora, tem-se, "em vez da literatura que fala do Brasil, que usa a cor local como valor (rentável) de troca, a literatura que busca se inserir, sem culpa, no movimento dos fluxos globais" (RESENDE, 2014, p.14).

Esquilos de Pavlov traz este deslocamento questionador de uma literatura nacional. Todo ambientado na Romênia e em países da Europa, a única referência que faz ao Brasil é de uma brasileira, também bolsista, com a qual Ciprian teve contato em sua residência na Alemanha. A brasileira se dedicava ao trabalho de discutir com uma moldava qual país era mais miserável, embora fosse filha de diplomatas e vivesse sempre a viajar. A brasileira, assim como a moldava, dizia ser de outra nacionalidade e negava seu país de origem, o que Ciprian critica: "Nenhuma das duas tinha passado fome e o fim do mundo deve ser mais questão de tempo do que de lugar" (ERBER, 2013a, p.58).

O poeta Ghérasim Luca, a cuja obra Laura Erber dedicou seus estudos, teve uma relação não de negação da pátria, como as personagens citadas, mas de abandono dela. Ele nasceu em Bucareste, na Romênia, mas foi para Paris, onde encontrou o grupo surrealista, passando a viver lá sem passaporte e adotando o francês como a língua de sua produção literária. O poeta ainda abandonou o próprio nome, Salman Locker. Quebrando qualquer noção de pertencimento, seja identitário, linguístico ou nacional, o trabalho de Ghérasim Luca consistia em torná-lo um estranho a si mesmo.

Assim como a obra de Ghérasim Luca, o livro de Laura Erber quebra qualquer relação de pertencimento. A partir disso é possível perceber a grande influência que esse poeta e a vanguarda surrealista exercem em sua obra. Não se trata apenas de uma simples referência acrítica, assinalada por Schøllhammer (2009) como um perigo da tendência de escritas de metaficção na literatura brasileira contemporânea: 
Literatura sobre literatura continua sendo um caminho frequentado na produção brasileira contemporânea [...] na maior parte dos casos, o gesto traz embutido o reconhecimento, mais ou menos humilde, dependendo do escritor, de que todos os que escrevem são leitores antes de se tornarem autores, anões sobre ombros de gigantes que, ao incluir em sua literatura suas referências literárias, pagam um tributo modesto. Hoje, entretanto, vivendo numa cultura da cópia, em que a aura da origem há muito se perdeu, o exercício deste procedimento exige um cuidado maior, pois, em vez de possibilitar um recuo e uma apropriação produtiva, pode tender a capturar o autor numa reverência parasitária e na sacralização que esvazia a potência de compreensão e de crítica. (SCHØLLHAMMER, 2009, p.143)

Em Esquilos de Pavlov, Laura Erber se apropria dos autores e artistas de sua coleção, muitos deles europeus e de vanguarda, e vai além da antropofagia oswaldiana de devorar as técnicas importadas e reelaborá-las com autonomia. Essa parece ser uma outra tendência da literatura brasileira contemporânea, como afirma Resende (2014, p.13):

Não se trata mais de devorar o que existe na vanguarda europeia para construir nossa própria arte. Trata-se, isso sim, de formar um sistema literário com conceitos próprios do que é literatura, propondo ainda suspender limites entre as escritas literárias e as diversas expressões artísticas, numa troca de linguagens efetiva e não de empréstimos, nas constituições de objetos artísticos múltiplos e não classificáveis em teorias ou nomeações redutoras.

Ao se apropriar do imaginário romeno e narrar as histórias das residências artísticas de Ciprian, Esquilos de Pavlov levanta a questão da identidade do artista enquanto sujeito em trânsito, sem lugar, um estranho para si mesmo e para o mundo. Conforme afirma Ciprian, "[a] pergunta não é: será que eu caibo no mundo ou entalo? Mas: será que caibo em mim mesmo ou afundo? Até onde vai meu Barco? Continuará sem mim?" (ERBER, 2013a, p. 166). A obra se apresenta, portanto, como um combate a qualquer tipo de pensamento condicionado e à instituição de conceitos limitados e totalizantes como a identidade, a nacionalidade, a arte e a própria literatura.

Dissolvendo fronteiras entre a literatura e outros tipos de arte, esta reunião de fragmentos que forma a obra Esquilos de Pavlov pode ser caracterizada a partir do que Florencia Garramuño (2014, p.91) chama 
de "formas de impertinência". A autora cita vários exemplos de obras de arte em processo em que se tem uma convivência de diferenças, seja de materiais, mídias, sentidos por meio dos quais estas obras são percebidas e, ainda, diferentes ordens, como nação e indivíduo. A heterogeneidade e a exploração da porosidade de fronteiras entre a literatura e as artes visuais, por exemplo, é, segundo Garramuño (2014, p.92), uma “condição da estética contemporânea na qual forma e especificidade parecem ser conceitos que não permitem dar conta daquilo que nela está acontecendo."

Garramuño (2014, p.99) cita a obra Bénédicte vê o mar, de Laura Erber, como exemplo dessas formas de impertinência que exigem do leitor uma leitura diferente da condicionada ou "disciplinada ou disciplinária". Trata-se de um livro-desenho, não impresso, mas disponibilizado na internet para ser visualizado em um computador ou tablet. Esquilos de Pavlov faz parte deste projeto de Laura Erber de testar possibilidades de interpretação para a imagem e a palavra, fugindo de um sentido condicionado e levando a liberdade de expressão e as possibilidades de significação ao extremo.

\section{Considerações finais}

Em um diálogo intenso com outras expressões artísticas e outras linguagens, entre elas a das artes visuais, Esquilos de Pavlov caracterizase como uma obra que explora diversas formas de não pertencimento, como a palavra e a imagem, o real e o ficcional, a ficção e a teoria. Justapondo essas diferenças em um procedimento alegórico bastante semelhante ao que faziam os surrealistas, a narrativa de Esquilos de Pavlov se apresenta de forma fragmentada, cabendo ao leitor percorrer o mesmo caminho da escritora ao produzir sua obra: juntar os fragmentos e guardá-los para, posteriormente, construir seu significado.

De colecionadora a alegorista, Laura Erber reúne os elementos de sua coleção como pesquisadora de Ghérasim Luca e do grupo surrealista, como estudante e participante de residências artísticas e constrói esta metaficção que transita entre o ficcional e o teórico e questiona os limites da arte e da literatura brasileira contemporânea.

\section{Referências}

AGAMBEN, G. O que é o contemporâneo? e outros ensaios. Tradução de Vinícius Nicastro Honesko. Chapecó, SC: Argos, 2009. 
BENJAMIN, W. O colecionador. In: BOLlE, W.; MATOS, O. C. F. (Org.). Passagens. Tradução de Irene Aron e Cleonice Paes Barreto Mourão. Belo Horizonte: UFMG, 2006. p. 237-246.

ERBER, L. Esquilos de Pavlov. Rio de Janeiro: Objetiva, 2013a.

ERBER, Laura. Uma nova romancista no olho do furacão. Pernambuco - Suplemento Cultural do Diário Oficial do Estado, Recife, 1 set. 2013 b. Entrevista. Disponível em: <http://www.suplementopernambuco.com. br/entrevistas/962-uma-nova-romancista-no-olho-do-furacao.html>. Acesso em 18 jan. 2016.

GARRAMUÑO, F. Formas da impertinência. In: KIFFER, A.; GARRAMUÑO, F. (Org.). Expansões contemporâneas: literatura e outras formas. Belo Horizonte: UFMG, 2014. p. 91-107.

JUNKES, L. O processo de alegorização em Walter Benjamin. Revista Anuário de Literatura, Florianópolis, n. 2, p. 125-137, 1994. Disponível em: $<$ https://periodicos.ufsc.br/index.php/literatura/article/view/5361>. Acesso em: 18 jan. 2016.

RESENDE, B. Possibilidades da nova escrita literária no Brasil. In: RESENDE, B.; FINAZZI-AGRO, E. (Org.). Possibilidades da nova escrita literária no Brasil. Rio de Janeiro: Revan, 2014. p. 9-23.

SCHØLLHAMMER, K. E. Ficção Brasileira Contemporânea. Rio de Janeiro: Civilização Brasileira, 2009.

Recebido em: 21 de maio de 2018.

Aprovado em: 9 de julho de 2018. 